\title{
DEGRADATION - PREDICTION MODELS OF THE RAILWAY TRACK QUALITY
}

\author{
Janka ŠESTAKOVÁ ${ }^{1, *}$, Libor IŽVOLT $^{1}$, Martin MEČÁR ${ }^{1}$ \\ ${ }^{1}$ Faculty of Civil Engineering, University of Zilina, Univerzitna 8215/1, 01026 Zilina, Slovakia. \\ corresponding author: janka.sestakova@fstav.uniza.sk.
}

\section{Abstract}

During the railway track life, its operational quality is represented by the key information on the extent and method of its degradation, applying indicators which were appropriately selected, surveyed and evaluated within the diagnostic activities. The paper describes methods and procedures of experimental verification, i. e. obtaining and evaluating operational quality indicators, representing design parameters and determining its quality. Determining the dependence of the values of different quality indicators on time or place of measurement allows to construct models of structure behaviour over its lifetime and to predict the time and place when and where the permissible boundary values of the qualitative indicators can occur. The paper presents the models prepared for monitored experimental sections in the Slovak Railways (ŽSR) network.
\end{abstract}

\section{Keywords:}

Railway track; Quality index; Monitoring; Assessment; Prediction.

\section{Introduction}

The quality of the railway track design generally describes its positive qualities, while the quality of the structure is established in accordance with the applicable standards and meets the user's requirements for reliability, availability, maintainability and safety. The track quality is represented by all its prescribed technical and ecological characteristics throughout its life, not only in its construction phase but also in the structure operation phase. The characteristics are represented by the set quality indicators (quality index). Quality indicators form the core of the diagnostics data and affect the structure of activities implemented to maintain or improve (rehabilitation) the prescribed operational quality of the structure. The nature and structure of the quality indicators of the relevant group of evaluated parameters is directly dependent on the initial (geometric and / or material) properties of the structure, or its structural element, and the way in which the structure, or its individual structural element, responds to the effects of traffic and non-traffic loads.

Since 2012, the Department of Railway Engineering and Track Management of the Faculty of Civil Engineering of the University of Žilina has been researching, among other railway engineering scientific issues, the quality monitoring of railway tracks, mostly in regard to unconventional superstructures applied in tunnels or bridge structures in the framework of Slovak Railways (ŽSR) infrastructure modernization. The Department has monitored and verified all of the unconventional superstructures which have been built in the ŽSR network after 2010. These sections were utilized as experimental sections of the Department.

The first objective of determining the quality indicators within the experimental verification (monitoring) is the identification of the "weak points" of the experimental sections, where the quality of the railway superstructure deteriorates the most. Monitoring was carried out by an electronic device with continuous scanning and recording of track geometry measurements. The second objective of the experimental verification is to evaluate the quality indicators and to develop a system of their application to model the prediction of the railway track quality development as a supporting decisionmaking tool for railway infrastructure managers. Models are created using methods of mathematical statistics and probability: regression and correlation analysis of diagnostic data. 


\section{Operational quality of railway track}

The operational quality of the railway track represents the capability of this structure to transmit the traffic load (static and dynamic load) and resist the effects of non-traffic load (climatic influences), without material or shape changes exceeding the permissible values set by the applicable norms. Such a condition represents the design as fault-free, ready, maintainable and safe. During the operational life, tracking and assessing the quality of the track design is addressed by its manager, who records and updates the prescribed data set.

The detection of the track operational quality in regard to railway tracks and structures focuses on the structure of railway superstructure and substructure, tunnels, bridges and structures similar to bridges, buildings and crossings. Tools of varying accuracy, scale and usability are available to identify and assess the railway track quality design in order to achieve the desired purpose and achieve the required level and quality.

The area of diagnostics to verify the operational quality of the structure, with respect to real operational practice, is the track geometry (quantities of the track layout and geometry). Track geometry quality is a key factor in the decision-making process of the rail infrastructure manager on the conditions for the operation and maintenance of the track.

\section{Experimental verification of the operational quality of experimental sections}

The objective of monitoring the design of the experimental sections of the modernized ŽSR lines is to monitor the development of the quality of the track geometry quantities in the transition areas between the classical structure of the railway superstructure (rail skeleton placed in a ballast bed) and the unconventional superstructure (ballastless track), including the immediate sections of the classic and unconventional construction before and after the transition area. The monitoring results should identify the "weak points" of the experimental sections where the structural quality of the railway superstructure is deteriorating. The quality of these locations in certain operational phases can only be represented by exceeded assessment level of the operational deviations set for the so-called determining quantities. The determining quantities for reliability and safety of railway operation are prescribed by [1] as the track alignment $S K(S L, S P)$ and the top level of rail (rails) VK $(V L, V P)$. An integral part of the monitoring is the detection of other quantities of track geometry, namely track gauge $(R K)$, change of gauge $(Z R)$, cant $(P K)$ and track twist $(Z K)$.

The model and practical behaviour of the construction described, e.g. in [2-7] indicates that in terms of the railway superstructure durability the problematic sections are the sections between the ballast bed structure and the ballastless track, i.e. the transition areas. The change in stiffness and response to the traffic load causes increased dynamic stress to the structure during the track operation. The load values are influenced by the speed of the railway vehicle and the ratio of stiffness, damping and the length of the transition area. The significant increase in traffic load leads to accelerated deterioration of the track geometry quality. (The quality degradation is represented mainly by changes in the position of the top level of rail. During the railway vehicle movement, this is reflected in the increased vertical acceleration of the vehicle.) Consequently, it calls for repair at shorter intervals.

The experimental verification of the operational quality of the experimental sections is aimed at determining track geometry quantities and detecting and evaluating track geometry quality indicators independently of supervision and inspection activities and technical facilities of the railway track manager (ŽSR), applying the conditions and methods set out in [1, 8-13]. In respect to this, the diagnostic tool used is the $K R A B^{T M}$-Light measuring trolley, i. e. an electronic device with continuous sensing and measurement recording (every $0.250 \mathrm{~m}$ ), designed to diagnose track geometry quantities. The measurement is carried out by contact of the sensing device with the track skeleton element (rails) of the diagnosed track and in an unloaded state (the weight of the diagnostic device is approx. $36 \mathrm{~kg}$ [14]). The implemented method of diagnostics is the main method for the speed zone $S Z 1$ to $S Z 4$ (up to $160 \mathrm{~km} / \mathrm{h}$ ) and a suitable supplementary track monitoring method implemented primarily as a loaded track measurement (in $S Z 5$ and $S Z 6$ ). The diagnostics carried out by this device is complex with respect to the simultaneous measurement and recording of all required quantities.

The verification of operational quality focuses on monitoring track geometry quantities in three experimental sections, two of which are part of the modernized railway line (experimental section no. 1 and no. 3) and the other section is a part of the modernization of the Bratislava tunnel no. 1 (experimental section no. 2). This paper only analyses the results of the monitoring of the first two 
experimental sections, which are similar to each other not only by their ballastless track structure $\left(\right.$ RHEDA $\left.2000^{\circledR}\right)$ but also by identical transition areas and connecting sections with the classic railway superstructure.

The experimental section no. 1: Turecký vrch tunnel, which has been monitored since 2012, consists of the following subsections (ESS):

- 1.1 - in the track no. 1 , near the southern tunnel portal,

- 1.2 - in the track no. 1, near the northern tunnel portal,

- 2.1 - in the track no. 2, near the southern tunnel portal,

- 2.2 - in the track no. 2, near the northern tunnel portal.

The experimental section no. 3, the railway bridge over the river Váh in Trenčín, which has been monitored since 2017, consists of the subsections:

- 3.1 - in the track no. 1 ,

- 3.2 - in the track no. 2.

The monitoring of the track geometry quantities (relative track position) of both experimental sections is carried out from putting track sections into operation at 6-month intervals (so-called spring and autumn measurements) and is supplemented by monitoring of the spatial position of the track (absolute track position) in the experimental sections in annual periodicity (as a part of the spring measurement). The diagnostics of the track spatial position is implemented using the diagnostic methods of geodesy and its results are presented in [2, 15-17].

The monitored experimental sections are also continuously diagnosed by visual diagnostic methods. The visual diagnostics is carried out in order to determine the state of the individual structural elements of the rail skeleton. With regard to the design of the railway superstructure of the experimental sections, specific attention in this area of monitoring is paid to the design of the ballastless track. The areas of visual diagnostics of these parts of experimental sections are:

- support slabs - documenting the dimensions, shape and behaviour of cracks and joints,

- pin joints - detection of damage to plastic joints and the pin-bolt joints,

- sleepers - sleeper loosening due to connection errors between the sleeper and the concrete filling (not assumed with the monolithic ballastless track),

- rail placement - cracking and breaking,

- supporting system of the ballastless track structure - extraordinary events and damage (significant changes in the substructure design, areas with accumulated loosened fastening elements, chipping and cracking of the support slab edges, failure of the support slab),

- other shortcomings (damage to the fastening system, deficient drainage system functionality, condition of sealing and side connections of long bridges and tunnels transitions [17].

The assessment of the visual diagnostics and geometric diagnostics of the spatial position of the track in the experimental sections no. 1 and no. 2 has been published in [15-17]. Fig. 1 and Fig. 2 demonstrate the segmentation of experimental sections no. 1 and no. 3 for the purposes of detecting and monitoring the development of the track geometry quality in accordance with the valid Slovak legislation. These figures also present information on the construction of the railway superstructure, substructure and the track alignment. The track alignment of the experimental sections is, in accordance with the valid legislation, considered the determining quantity for the quality of track geometry assessment. Both experimental sections are included in SZ4. 


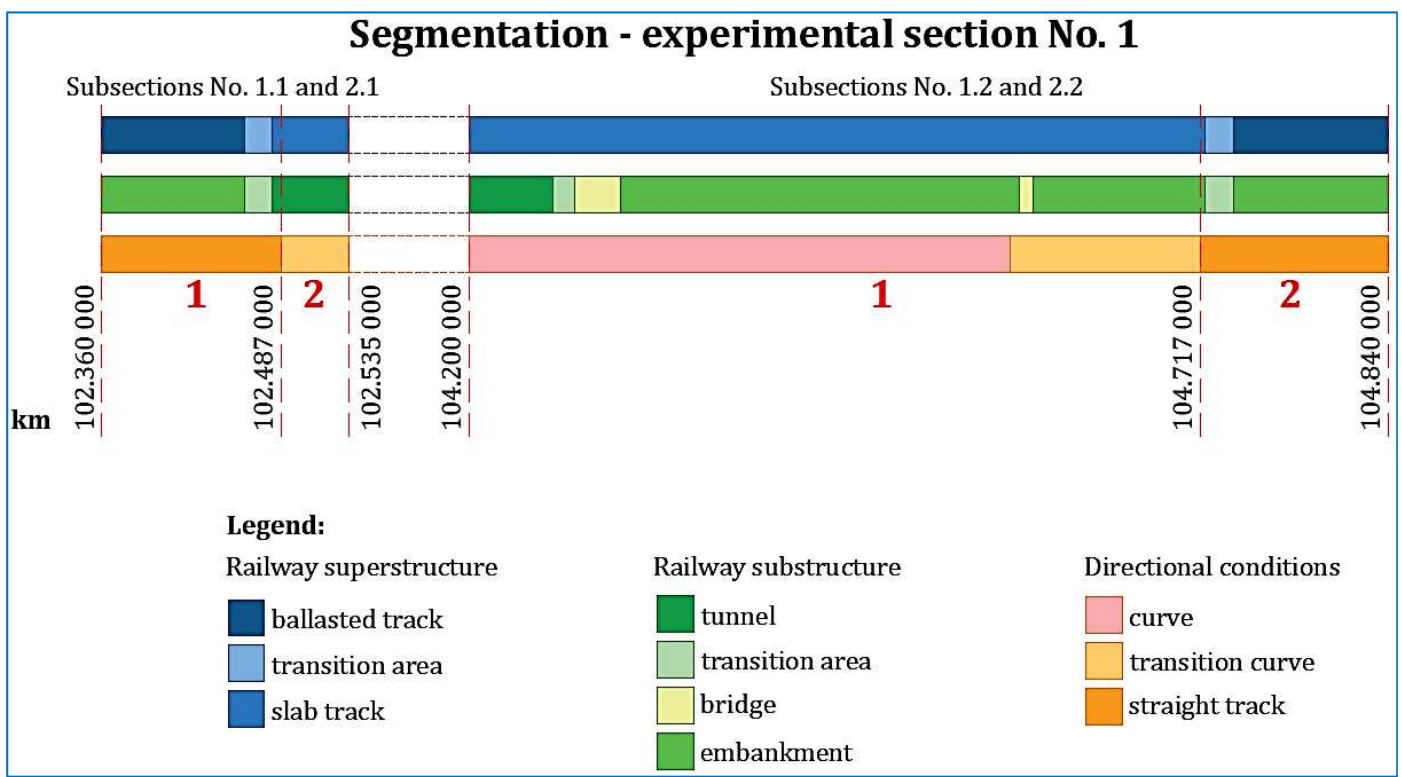

Fig. 1: Graphical overview of diagnostic segmentation of the experimental section 1, [18].

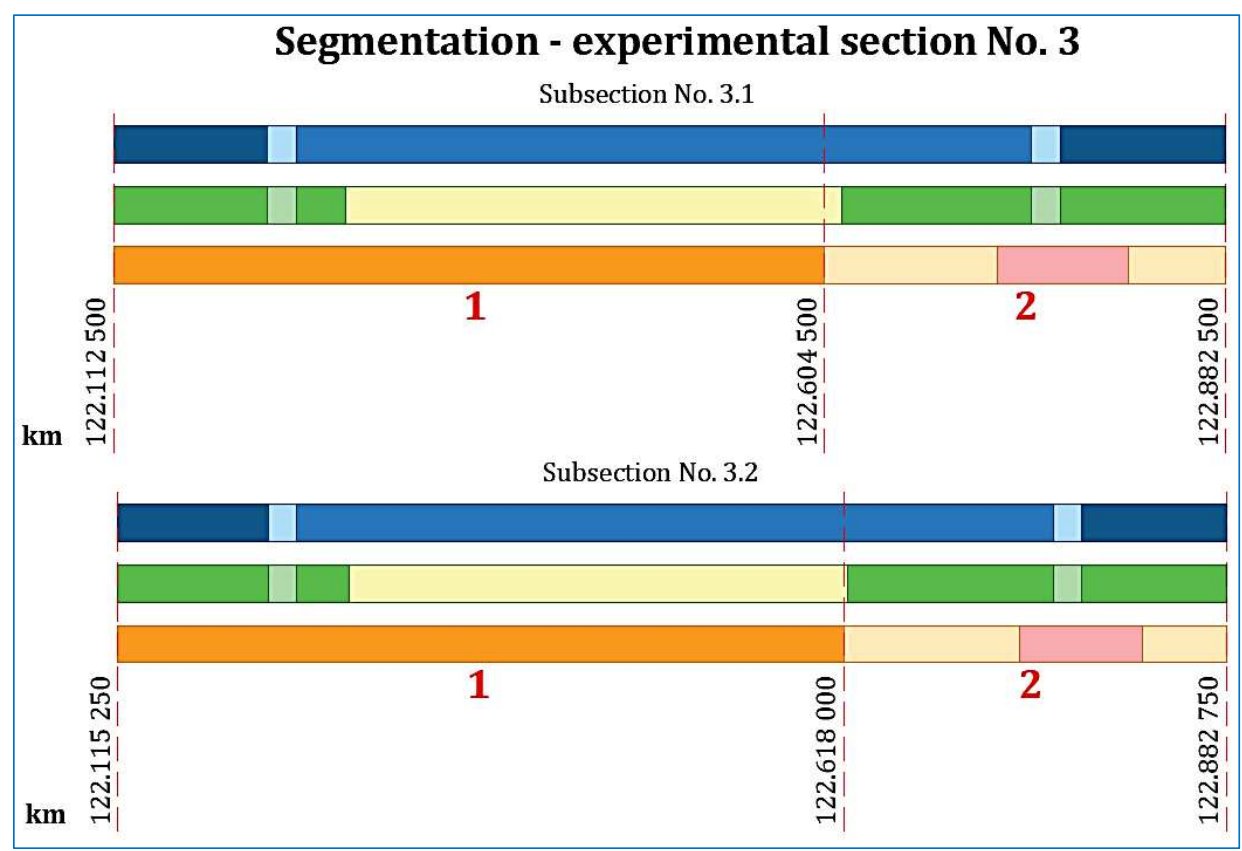

Fig. 2: Graphical overview of diagnostic segmentation of the experimental section 3, [18].

The standardized values of the monitored parameters are prescribed by the legislative document [6] through the permissible deviations or permissible maximum values of geometric track quality on the levels of:

- installation requirements, or values of the geometrical quality of the track for the acceptance of construction work in the track with new material $(M S O)$, or possibly renewed and recycled material and for acceptance of other work,

- maintenance limits $(P O)$, or values of the geometrical quality of the track:

- for $A L$ level - alert limit,

- for IL level - intervention (repair) limit,

- maintenance limits, or values of the geometrical quality of the track for the IAL level immediate intervention limit.

The ŽSR norm [13] defines, in accordance with [1], the track geometry quality indicators represented by:

- the occurrence of local errors representing the track geometry ( $S L, S P, R K, Z R, P K, Z K, V L$, $V P)$ : location (stationing), the size of the deviation from the prescribed assessment level, 
- value of the quality number $(Q N)$ of the assessed section,

- values of standard deviation (SDO) of the average values of track geometry quantities $S K, R K$, $P K, V K$,

- values of quality marks $(Z K v)$ of quantities $S K, R K, P K, V K$.

The detection and subsequent evaluation of track geometry quality of the experimental section no. 1 (partially measured in four sub-sections) has been carried out continuously since 2012 at approximately 6-month periodicity. The first measurement of the track geometry of this experimental section was made as a measurement for the acceptance of construction work in the track and switches with new material (MSO level). Other measurements are defined as operating (PO1 to PO13) diagnostics $(A L, I L, I A L)$. In the sub-sections of experimental section no. 1, a repair intervention was carried out in the railway superstructure with the ballast bed and in the transition area (corrections of the track alignment and the top of rail position), after the MSO measurement in the summer or the summer or autumn 2012. (Local errors were detected in all sub-sections also by the method of continuous measurement recording under load - by the track geometry measuring vehicle). Another repair intervention was implemented after measuring PO4 in autumn 2014 and before measuring $P O 10$ in autumn 2017. (The VL and VP errors were detected only in sub-sections 1.1 and 2.1. However, the railway infrastructure manager has made a preventive repair in subsections 1.2 and 2.2).

The diagnostics and subsequent assessment of the track geometry quality of the experimental section no. 3 (partially measured in two sub-sections) have been taking place since July 2017 and a 6month measurement period is assumed. The first measurement of the experimental section geometry in SZ4 was in the track no. 1, and it was performed as a measurement for the construction work acceptance in the track and switches with the new material (MSO). The first geometry measurement in track no. 2 is considered to be an operational measurement $(A L, I L, I A L)$ since it was performed approx. 70 days after the start of operation in this track.

\section{Use of track geometry quality indicators for its development prediction}

The rail infrastructure manager used the track diagnostic results to plan the maintenance and repair work. The planning of track geometry corrections at ŽSR is currently implemented by evaluating local errors, $S D O$ values and section $Q N$, in the safety maintenance scheme. This means that after an error is detected, corrective action is taken. Correctly processed and interpreted diagnostics data can serve as a suitable decision-making tool for early detection of the quality degradation trend.

The diagnostic data obtained as a part of experimental verification of track geometry quality of the experimental sections are used in the design of degradation models and prediction of future track geometry quality development. The concept of models is a supportive tool for planning preventive repair work to address low-severity and small-scale errors. Diagnostic data pooling for modelling respects the principle of segmentation of monitored sections of the operational track geometry quality verification. The maximum length of the segment is $1.000 \mathrm{~m} \mathrm{[13],} \mathrm{with} \mathrm{the} \mathrm{decisive} \mathrm{technical} \mathrm{factor}$ being the parameters of the track alignment (straight section/section in the transition curve, a section in the arc). This factor is conditioned by the use of the RK assessment levels defined in [8].

The models apply mathematical statistics and probability methods. In the defined boundary conditions, we only determined the mathematical context in which it is not possible to specify the causes and consequences of phenomena related to the development of a particular quantity. Modelling only focuses on three groups of diagnostic data, namely [16]:

1. relative deviations of the track alignment and the top of rail position / relative to the centre of the quantity; the signals of the quantities are filtered in the $D 1$ zone:

1.a $S K \_d y n \_L, S K \_d y n \_P, V K \_d y n \_L$ and $V K \_d y n \_P$ values for the models of the sectional course of the measured deviations of the determining quantities $S L, S P$, or VL, VP,

1.b absolute values of maximum deviations $|S L, S P|_{\max },|V L, V P|_{\max }$, which are identified for the determining quantity as the greater of the absolute values of the maximum deviation from the central line for the left and right rail in each measurement; Fig. 3 and Fig. 6 demonstrate the time course of the average value of the change of deviation $|V L, V P|_{\max } / t$,

2. standard deviations $S D O_{S K}, S D O_{V K}$; Fig. 4 and Fig. 7 demonstrate the time course of the average standard deviation $S D O_{V k} / t$,

3. section quality numbers (Fig. 5 and Fig. 8).

The individual models show the dependencies of the data group values on the measurement 
location or on the measurement time. The model data does not include the indicators that have not been so far considered the main parameters of the quality assessment of the track (quality marks, overall quality marks, tamping marks). The principles of the created predictive models can also be used for other measured and monitored railway sections. However, the condition is a sufficient range of diagnostics data of a comparable structure and data synchronization according to the position of the diagnosed structure. The accuracy of the application of the created models in practice will be greatly enhanced by completing the database of data from regular measurements and by adding information on corrective interventions, in particular, the parameters of track alignment, top of rail position and the cant.

The degradation-prediction models of the track geometry quality of the experimental section no. 1 use, with respect to the continuity of development interrupted by repairs, the diagnostic data obtained after implementation, i. e. operational measurements PO5 to PO9 and operational measurements $P O 10$ to PO13. (These were the measurements, carried out and evaluated by June 2019). The degradation-prediction models of track geometry quality of the experimental section no. 3 utilize the data from the diagnostic measurement performed and evaluated from the 2nd measurement until June of 2019 , within the experimental quality validation, in the track no. $1-P O 1$ to $P O 4$, and in track no. $2-P O 2$ to $P O 5$. To determine the regression equations of the dependence of the maximum deviation value of the determining quantity or the time and quality index, for each segment of experimental section no. 1, we used a total of 5 values representing 5 measurements, or 4 values from 4 measurements. In the experimental section no. 3, 4 values of the determining quantity or the quality index from 4 measurements are used in all segments.

The graphical representation of the relationships of correlation and regression analyses of the maximum deviation value of the determining variable or the quality and time index is shown in Fig. 3 to Fig. 8. It is presented for the diagnostic segments whose quality decreases the most rapidly in terms of the maximum value of the quality indicator course (experimental section no. 1), or for all segments (experimental section no. 3). For the experimental section no. 1, they demonstrate the trends in two cycles of operation separately, before and after the track geometry correction performed in October 2017.

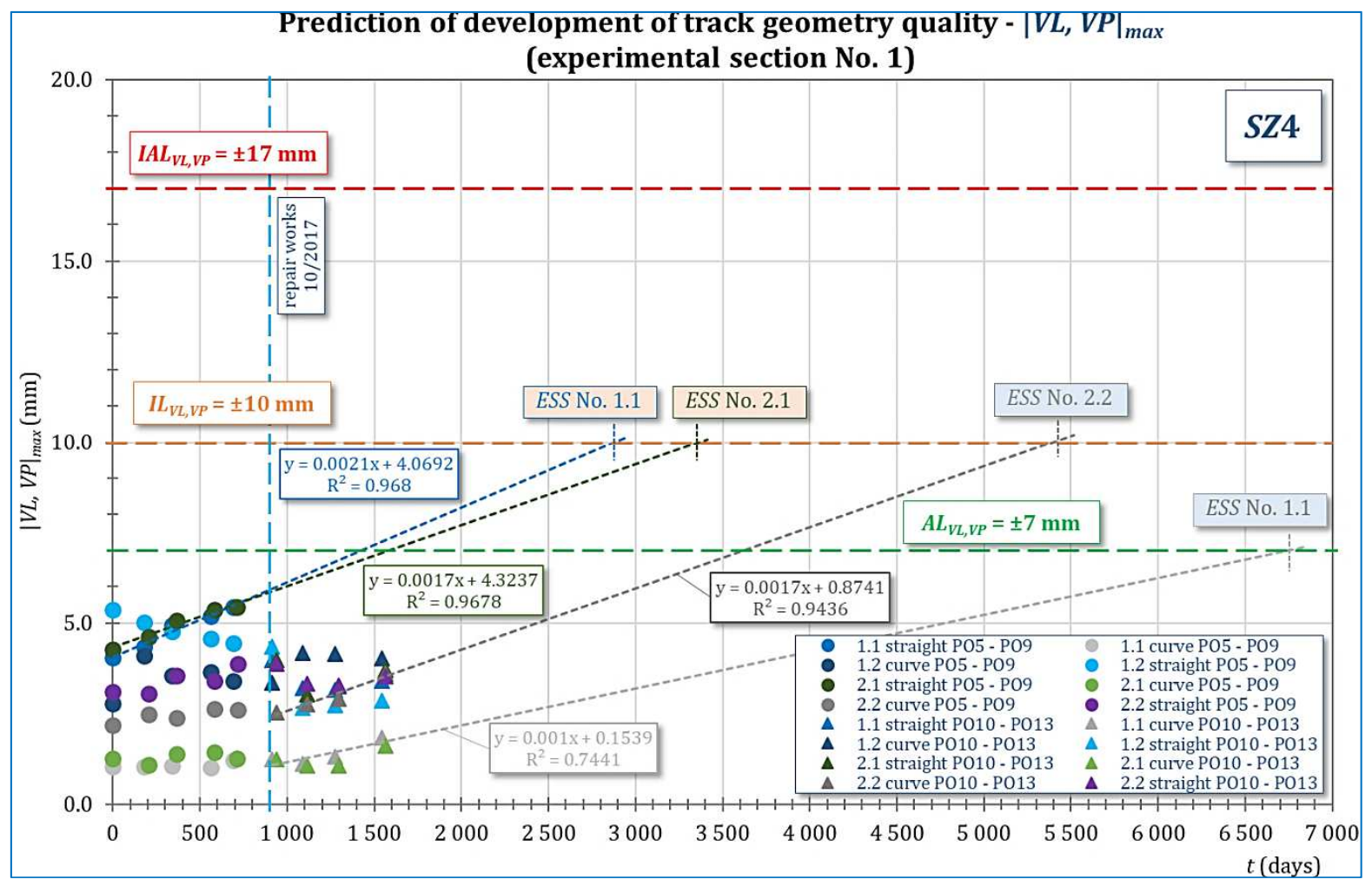

Fig. 3: Experimental section no. 1 - time course of the average value of the change of deviation $\mid V L$, $\left.V P\right|_{\max } / t$. 


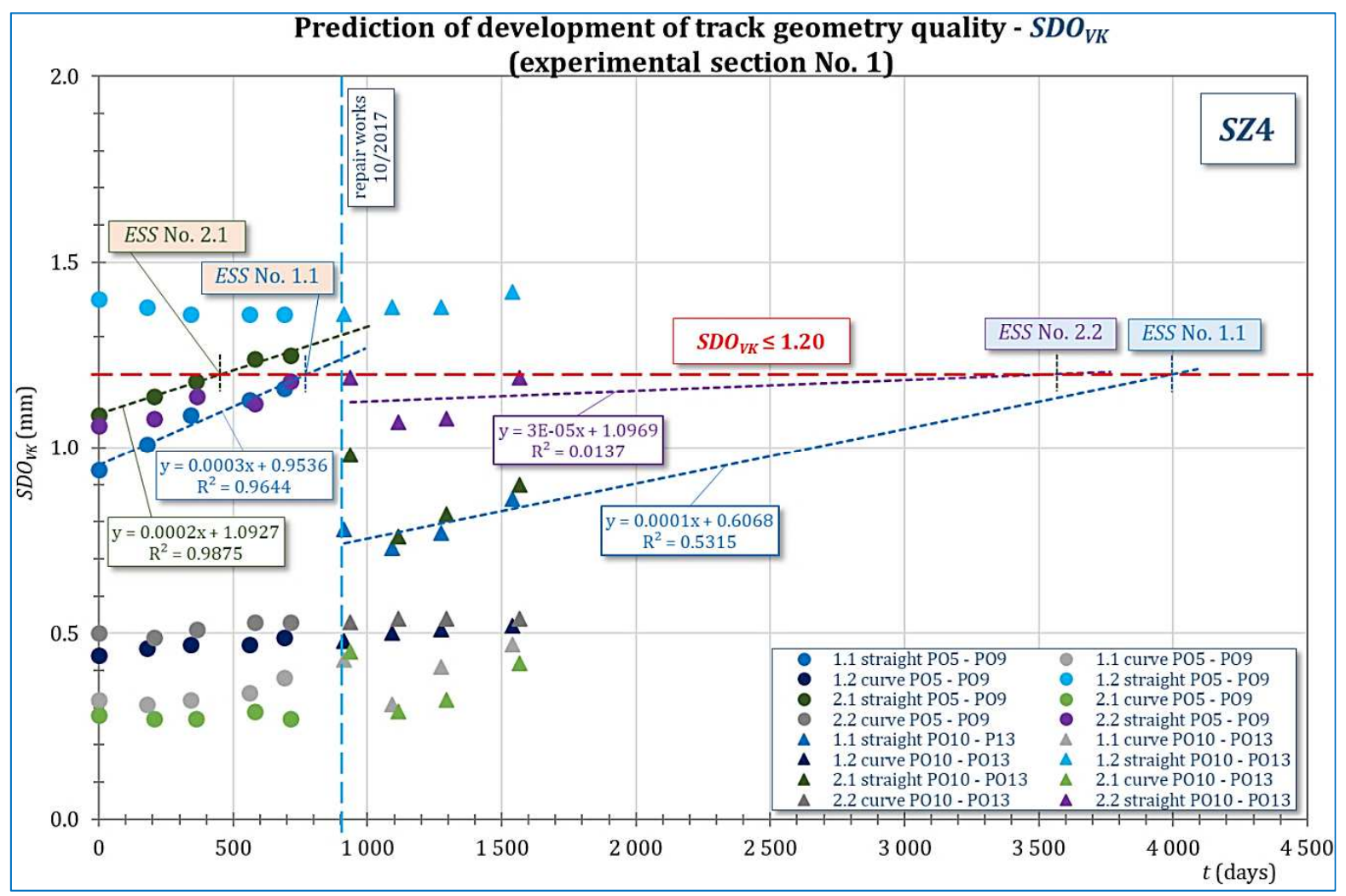

Fig. 4: Experimental section no. 1 - time course of the standard deviation $S D O_{V K} / t$.

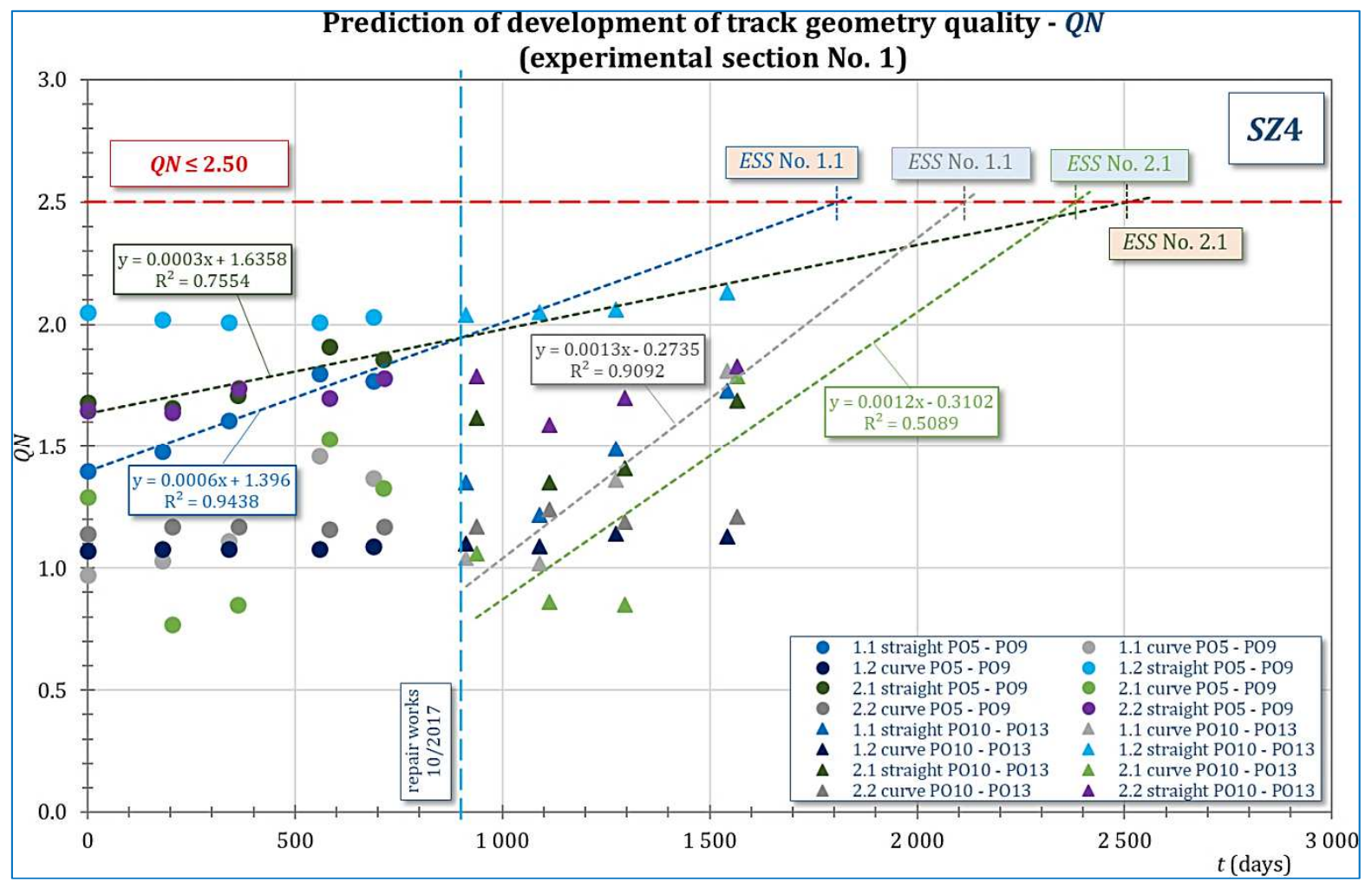

Fig. 5: Experimental section no. 1 - time course of the section quality number $(Q N / t)$. 


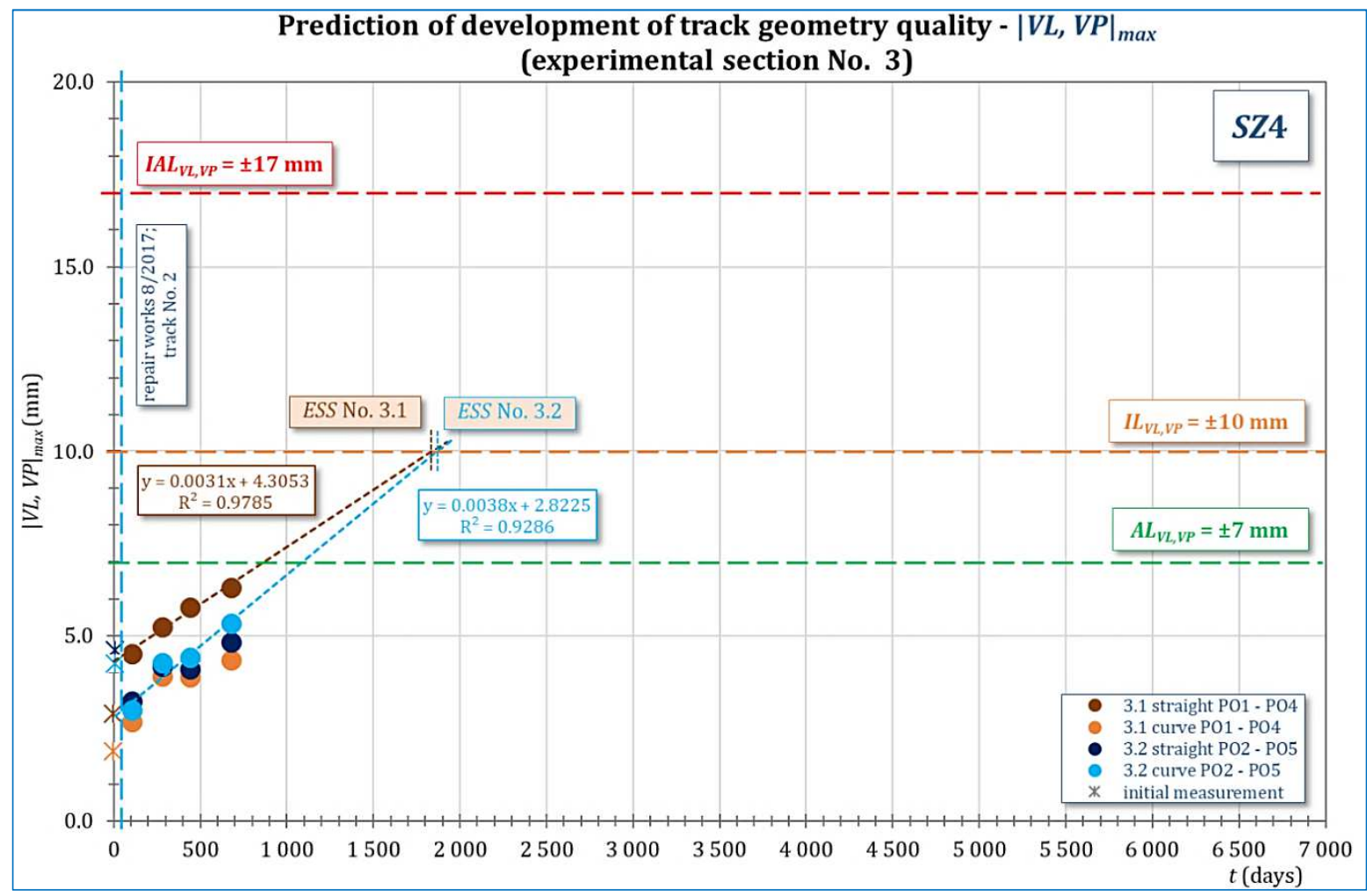

Fig. 6: Experimental section no. 3 - time course of the average value of the change of deviation $\mid V L$, $\left.V P\right|_{\max } / t$.

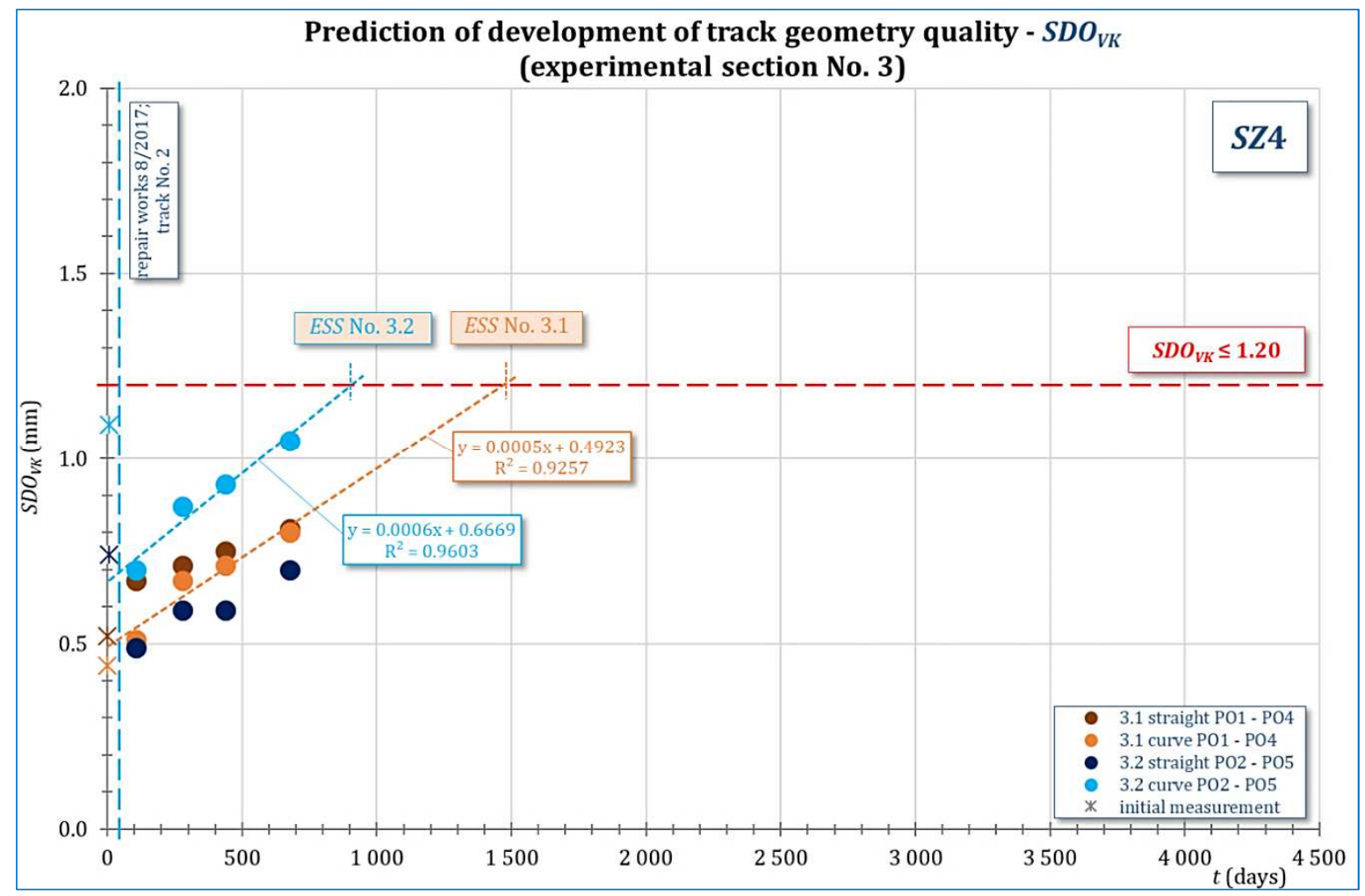

Fig. 7: Experimental section no. 3 - time course of the standard deviation $S D O_{V K} / t$. 


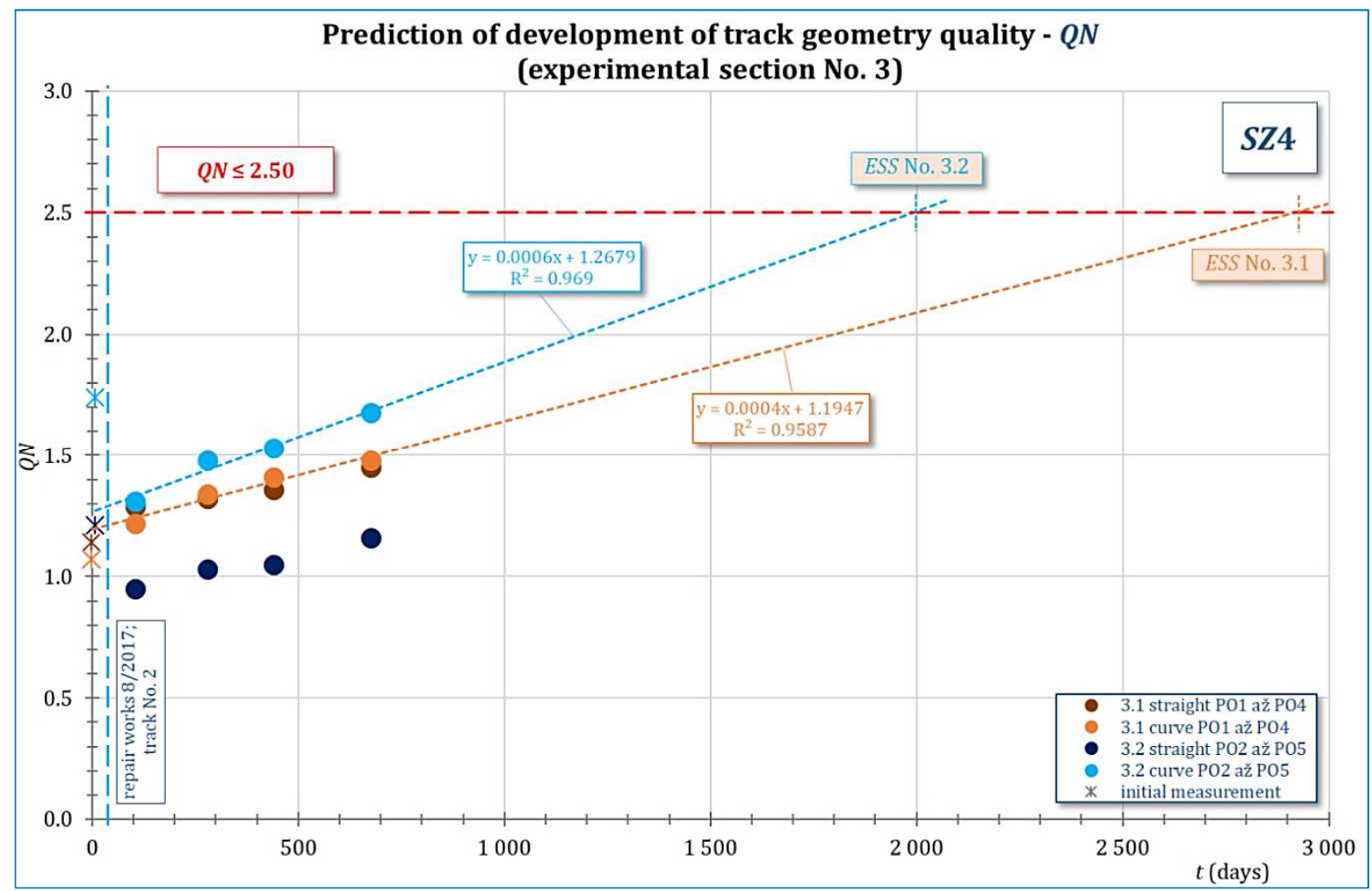

Fig. 8: Experimental section no. 3 - time course of the section quality number ( $Q N / t)$.

\section{Conclusions}

The results of the regression and correlation analysis of the diagnostic data confirm that in the degradation-prediction models 1 (1.a, 1.b), 2 and 3 , the maximum deviation values of the determining quantities $(S K, V K)$ and quality indexes $(S D O, Q M)$ are linearly dependent in relation to time, in both experimental sections.

According to statistical models, the maintenance limit value for the standard deviation of the quantity $V K\left(S D O_{V k}\right)$ will be the fastest reached in both experimental sections. The initiation of immediate implementation of corrective action or planning and organization of repair work is currently governed by the most unfavourable prediction of the track quality development in the models $\mid V L$, $\left.V P\right|_{\max } / t$ and $Q N / t$. This procedure is characteristic of a safety system for the railway superstructure maintenance. Using predictive models $S D O_{V k} / t$, and $S D O_{S K} / t$, or their combination, is conditioned by a change in the maintenance system from safety to preventive, in which for planning and organizing preventive track geometry corrections the SDO limit value is achieved or exceeded.

\section{Acknowledgement}

The article is a partial output of the solution of the grant task VEGA No. 1/0275/17 Application of Numerical Methods in Defining the Change of the Geometric Position of a Track.

\section{References}

[1] STN EN 13848-6 (73 6315), 2014: Railway Applications - Track - Track Geometry Quality - Part 6. Characterisation of Track Geometry Quality.

[2] IŽVOLT, L. - ŠESTAKOVA, J. - ŠMALO, M.: Analysis of Results of Monitoring and Prediction of Quality Development of Ballasted and Ballastless Track Superstructure and its Transition Areas. Communications - Scientific Letters of the University of Zilina. Vol. 18, No. 4, 2016, pp. 19-29, http://komunikacie.uniza.sk/index.php/communications/article/view/ 284.

[3] IŽVOLT, L. - ŠMALO, M. - ŠESTÁKOVÁ, J.: Impact of Operation on the Geometric Parameters of the Track in Ballastless Track Transition Area. MATEC Web of Conferences, Dynamics of Civil 
Engineering and Transport Structures and Wind Engineering - DYN-WIND'2017, Vol. 107, 2017, article num. 00019, https://doi.org/10.1051/matecconf/ 201710700019.

[4] STARK, T. D. et. al.: Effect of Unsupported Ties at Transition Zones. Proceedings of Railway Engineering 2015, $13^{\text {th }}$ International Conference, Edinburgh, Scotland, 2015, 13 p. http://tstark.net/wp-content/uploads/2016/07/CP143.pdf.

[5] ŠESTÁKOVÁ, J.: Quality of Slab Track Construction - Track Alignment Design and Track Geometry. Civil and Environmental Engineering, Vol. 11, Issue 1, 2015, pp. 2-9 https://doi.org/10.1515/cee-2015-0001.

[6] ŠMALO, M.: Diagnostics of Track Quality of Ballastless Track and Transition Areas in Vicinity of Portals of Tunnel Turecky Vrch. Civil and Environmental Engineering, Vol. 12, Issue 1, 2016, pp. 212, https://doi.org/10.1515/cee-2016-0001.

[7] IŽVOLT, L. - ŠMALO, M.: Assessment of Track Geometry Quality from the Aspect of Safe and Reliable Operation of the Railway Track. Procedia Engineering, XXIV R-S-P seminar Theoretical Foundation of Civil Engineering, Vol. 111, 2015, pp. 344-350, http://www.sciencedirect.com/science/article/pii/S187770581501348X.

[8] STN 73 6360-2, 2015: Railway Applications. Track. Part 2, Acceptance of Construction Works, Maintenance Works and Assessment of Service Condition Track Gauges $1435 \mathrm{~mm}$.

[9] STN EN 13848-1 + A1 (73 6315), 2009: Railway Applications. Track. Track Geometry Quality. Part 1: Characterisation of Track Geometry.

[10] STN EN 13848-4 (73 6315), 2011: Railway Applications - Track - Track Geometry Quality - Part 4, Measuring Systems - Manual and Lightweight Devices.

[11] STN EN 13848-5 (73 6315), 2010: Railway Applications - Track - Track Geometry Quality - Part 5, Geometric Quality Levels - Plain Line.

[12] Regulation of Slovak Railways No. Z 10, 2014: Rules of Technical Operation of Railway Infrastructure.

[13] Regulation of Slovak Railways SR 103-7 (TS), 2017: Measurement and Evaluation of the Track Gauges $1435 \mathrm{~mm}$ and $1520 \mathrm{~mm}$ by Measuring Trolley for Railway Track Geometry KRAB.

[14] Light Measuring Trolley for Railway Track Geometry KRAB-Light, [online]. [Viewed 2016-08-20], http://www.kzv.cz.

[15] IŽVOLTOVÁ, J. - VILLIM, A. - PISCA, P.: Analysis of Height Changes of Ballastless Track. (In Slovak). Geodesy, Cartography and Geographic Information Systems, Proceedings of the $8^{\text {th }}$ Scientific International Conference, Technical University of Kosice, Kosice, 2014, 6 p.

[16] IŽVOLTOVÁ, J. et al.: Precision Analysis of Height Measurements Realized on Ballastless Track. Communications - Scientific Letters of the University of Zilina, Vol. 16, No. 4, 2014, pp. 63-67, http://komunikacie.uniza.sk/index.php/communications/article/view/578.

[17] ŠMALO, M.: Utilization of Track Monitoring with Unconventional Structure of Railway Superstructure in Maintenance. PhD. Thesis (in Slovak). University of Žilina, Slovak Republic, 2017, $142 \mathrm{p}$.

[18] ŠESTÁKOVÁ, J.: Diagnostics of Operational Quality of Railway Track and its Influence on Renewal Work Planning. Habilitation thesis (in Slovak). University of Žilina, Slovak Republic, 2017. $164 \mathrm{p}$. 